\title{
RBEP
}

\section{Um programa de formação de professores: o caso da Universidade de São Paulo}

Maria Angélica Penatti Pipitone

Edna Maura Zuffi

Noeli Prestes Padilha Rivas

\section{Resumo}

Relata o percurso, da definição à implantação, a partir de 2004, do Programa de Formação de Professores da Universidade de São Paulo (USP). Toma como recurso de análise a trajetória de implantação do referido Programa em duas unidades dessa universidades - nas licenciaturas em Ciências Agrárias e Ciências Biológicas da Escola Superior de Agricultura "Luiz Queiroz" (Esalq) e na licenciatura em Matemática do Instituto de Ciências Matemáticas e de Computação (ICMC) -, a partir do estudo das diretrizes oficiais para a formação de professores e dos aspectos teórico-metodológicos que permeiam estas normas legais. O processo, aqui trazido, aponta desafios de toda ordem, como o desenvolvimento dos conceitos de estágio supervisionado, de prática como componente curricular e de atividades acadêmico-científico-culturais, além das dificuldades inerentes à construção de uma nova identidade docente no interior dos cursos de licenciatura e na própria universidade.

Palavras-chave: formação de professores; licenciaturas; ensino. 


\section{Abstract \\ A teacher training program of Universidade de São Paulo: case study}

This article describes the trajectory of the Universidade de São Paulo (USP) Teacher Training Program since 2004, from its creation to its implementation. We analyze this implementation process in two faculties of the university - Agrarian Sciences and Biological Sciences Programs of the Escola Superior de Agricultura "Luiz de Queiroz" (Esalq) and Mathematics Program of the Instituto de Ciências Matemáticas e de Computação (ICMC) - considering the official guidelines on teacher training, and the theoretical and methodological aspects encompassing those rules. The process report presented here points out to challenges like developing concepts like supervised internship, practice as a curricular component, and culturalscientific-academic activities, as well as dealing with inherent difficulties to build a new identity in the courses and in the university.

Keywords: teacher training; bachelor degree; education.

\section{Introdução}

De acordo com Penin (2001, p. 325):

As Diretrizes Nacionais para a Formação de Professores, assim como as normatizações dos Conselhos Estaduais de Educação apresentam elementos importantes para os estados e suas instituições, sobretudo as universidades, refletirem e definirem suas próprias políticas de formação de professores, assim como seus projetos de cursos, no pleno uso de sua autonomia. No caso da USP, o momento atual reveste-se de uma importância ímpar para acertar contas pendentes desde sua fundação no que diz respeito a uma política explícita e a uma proposta mais articulada e efetiva de formação de professores para a escola básica.

1 A Comissão Permanente de Licenciatura (CPL), criada em 2001, foi presidida pela professora Dra Sônia T. de Souza Penin, depois pelo professor Dr. José Sérgio Fonseca de Carvalho, pelo professor Dr. Nélio Bizzo, quando a CPL transformou-se em Comissão Interunidades de Licenciatura (CIL) e, mais recentemente, tem sido presidida pela professora Dra Iole de Freitas Druck. É vinculada à Pró-Reitoria de Graduação e formada por docentes e alunos de todas as unidades que têm a licenciatura como opção aos seus alunos. Ê uma comissão articuladora da política de formação de professores da USP.

Essa afirmação ilustra bem o clima que motivou a criação da Comissão Permanente de Licenciatura (CPL), em 2001, e que se consubstanciou na elaboração e aprovação do Programa de Formação de Professores da Universidade de São Paulo (PFP).

O presente trabalho relata a implantação do referido Programa, em duas unidades da USP, a partir da atuação da Comissão Interunidades de Licenciatura (CIL). ${ }^{1}$ Tendo como referencial as novas diretrizes de formação apontadas pela comunidade científica, o estudo faz uma análise dos desafios colocados pelas diretrizes oficiais de formação de professores e os processos de mudança desencadeados pela Universidade de São Paulo. Para tal, utiliza a técnica da análise documental para levantar aspectos preponderantes dessa implantação. 


\section{Percursos formativos: focalizando as lentes nos cursos de licenciatura}

É imperioso registrar que os cursos de licenciatura ocupam menor espaço na hierarquia científica das universidades, o que tem comprometido sua identidade cultural e política. Os cursos de graduação, na modalidade bacharelado, têm sido hegemônicos, pois contemplam "os saberes científicos", enquanto que os de licenciatura, por incluírem em seus currículos os denominados "saberes pedagógicos", têm ficado relegados ao segundo plano.

Essa situação se arrasta até o inicio do século 21, quando emerge um conjunto de pareceres e resoluções decorrentes da Lei de Diretrizes e Bases da Educação Nacional - LDB (Lei no 9.394/96), que irá disciplinar a formação de professores, culminando em um amplo processo de reestruturação dos cursos de licenciatura.

Nessa direção, a Universidade de São Paulo instituiu, em 2004, o PFP, ${ }^{2}$ estabelecendo as bases e as condições de integração de formação inicial de docentes para a educação básica em cada unidade e entre as diferentes unidades, assim como entre a USP e os sistemas de educação básica do Estado e dos municípios circunvizinhos aos campi da instituição.

A CPL, em 2001, foi composta por representantes de 17 unidades da USP, que ofereciam um ou mais cursos de formação de professores/licenciaturas. Esse grupo, ultrapassando a significativa necessidade de atender tanto às exigências legais quanto à formação de professores, passou a elaborar, consolidar e conferir status de real importância às discussões sobre a qualidade dessa formação no interior dessa universidade.

Desde a origem, as discussões da CPL foram pautadas no atendimento às bases legais oriundas do Ministério da Educação (MEC), sem, contudo, contrariar a diversidade de expectativas e de formas de organização provenientes das diferentes unidades da USP. Uma medida de êxito para o enfrentamento dessas diferenças, por parte dos membros da CPL, constituiu-se do diálogo e do compromisso permanente com uma ação integrada e renovadora visando à promoção da qualidade dos cursos de formação de professores.

\section{O Programa de Formação de Professores da USP: entre o instituído e o desejado}

A seguir, descrevemos os principais eixos do PFP, bem como seu atual estágio de implantação. O documento apresenta os princípios e objetivos, a organização e articulação das licenciaturas, a estrutura mínima comum às licenciaturas e as condições de implementação.

\section{Princípios e objetivos orientadores}

Entre esses princípios, torna-se evidente e imperiosa a constatação de que a licenciatura deve deixar de ser entendida como uma superposição
2 Aprovado pelo Conselho de Graduação em 19 de fevereiro de 2004 e pelo Conselho Universitário em 25 de maio de 2004. 
do bacharelado, situação na qual o saber disciplinar específico antecede o aprendizado do saber pedagógico. Essa evidência é destacada também nos documentos legais, como a LDB, o Plano Nacional de Educação, bem como entre as Diretrizes para a Formação de Professores.

De forma contrária à justaposição das formações do bacharelado e da licenciatura, o PFP-USP prevê uma integração entre as áreas de formação, privilegiando a docência, a vida escolar e as instituições educativas como objetos a serem enfatizados em qualquer projeto que vise à preparação para o exercício profissional na escola contemporânea. A formação de professores na USP deve levar em conta a escola pública como prioritário foco de interesse em pesquisas, projetos e intervenções. A indissociabilidade entre ensino, pesquisa e extensão precisa ser garantida nos cursos de licenciatura e na perspectiva da formação continuada dos professores egressos desses cursos. Além disso, considerou-se também a formação desses docentes por meio de estruturas curriculares integradas e flexíveis, de forma a preservar as perspectivas da universidade e, sobretudo, as peculiaridades formativas de cada unidade de ensino.

Assim, a formação de professores deve partir da noção de que a docência não se realiza num quadro abstrato de relações individualizadas de ensino e aprendizagem, mas dentro de um complexo contexto social e institucional (USP, 2004, p. 4-8).

Além dos princípios, o PFP definiu cinco objetivos em consonância com o objetivo geral dos cursos de graduação da USP, que é a "formação de um profissional competente, socialmente crítico e responsável pelos destinos de uma sociedade que se deseja justa, democrática e auto-sustentável" (USP, 2004, p. 7). São eles:

- Compreender o contexto da realidade social da escola brasileira - seus valores, representações, história e práticas institucionais -, de modo a poder assumir uma postura crítica e responsável pela transformação dessa realidade, contribuindo para o desenvolvimento de novas formas de interação e de trabalho escolar.

- Orientar suas escolhas e decisões profissionais por princípios éticos, pela superação de preconceitos, pela aceitação da diversidade dos alunos, partindo do princípio de que todo aluno é capaz de aprender.

- Compreender os processos de ensino e de aprendizagem e reelaborar os saberes e as atividades de ensino, sempre considerando a realidade social, os objetivos da escola básica, o cotidiano escolar e as experiências dos alunos.

- Criar, implementar, avaliar e aperfeiçoar projetos de ensino e de aprendizagem, articulando-os com outras áreas do conhecimento e estimulando ações coletivas na escola, de modo a caracterizar uma nova concepção de trabalho educacional.

- Investigar o contexto educativo em sua complexidade e analisar sua prática profissional, bem como as práticas escolares, tomandoas como objeto de reflexão, de modo a poder criar soluções 
mais apropriadas aos desafios específicos que enfrenta e dar prosseguimento ao processo de sua formação continuada.

- Para efetivar tais objetivos, tão-somente uma reforma curricular não é suficiente. Faz-se necessário um esforço integrado e uma organização institucional capazes de implementar os princípios e objetivos desse Programa e sugerir investigação e proposições inovadoras aos diferentes cursos de formação de professores.

\section{Organização e articulação das licenciaturas}

No início do ano de 2001, a Pró-Reitoria de Graduação da USP criou a CPL e atribuiu aos seus representantes a tarefa de formular uma proposta de programa de formação de professores. A referida comissão iniciou seus trabalhos partilhando as experiências vividas pelos participantes das diferentes unidades e examinando as publicações que registram os debates ocorridos nas últimas décadas, assim como os documentos legais referentes ao assunto. Os mecanismos institucionais de organização e articulação das diferentes licenciaturas, mais do que simplesmente sugerirem caminhos fixos e únicos, têm fomentado a constante proposição de soluções inovadoras por parte de docentes, faculdades e institutos envolvidos com a formação de professores.

Naquele momento de instalação, a CPL tinha como propostas: a) a reativação ou a instalação de Comissões Coordenadoras de Curso(s) de Licenciatura (CoCs) ${ }^{3}$ em cada unidade que ofereça a licenciatura; b) a criação, na Faculdade de Educação, de uma Comissão de Acompanhamento das Licenciaturas (CAL/FE); ${ }^{4}$ c) a criação de uma Comissão Interunidades das Licenciaturas (CIL). A esta comissão coube a discussão e a proposição de diretrizes gerais da política de formação de professores da USP e das normas e procedimentos do funcionamento das licenciaturas, encaminhando ao Conselho de Graduação os resultados de seu trabalho.

Duas versões preliminares das propostas foram apresentadas em audiências públicas (2001 e 2002), e as sugestões então formuladas passaram a ser analisadas pela comissão. A proposta definitiva, aprovada em 2004, foi denominada Programa de Formação de Professores. Esse Programa incorporou várias sugestões e procurou compatibilizar expectativas muitas vezes bastante diferentes, embora igualmente legítimas.

\section{Estrutura mínima comum às licenciaturas: caracterização, componentes comuns e estágio supervisionado}

Para a elaboração dessa estrutura curricular, a CIL propôs uma estrutura mínima comum às licenciaturas, ${ }^{5}$ no que diz respeito à formação integrada. Essa estrutura curricular atende às resoluções vigentes, tanto no âmbito do Conselho Nacional de Educação (CNE) como no do Conselho Estadual de Educação de São Paulo. Tal estrutura está organizada em

\footnotetext{
$\overline{3 \text { As Comissões Coordenadoras }}$ de Cursos (CoCs) foram criadas pela Resolução COG nº 3.740, de 25 de setembro de 1990 , que estabelece, em seu artigo primeiro, que "cada curso ou habilitação, quando ministrado por mais de uma unidade, será coordenado por uma Comissão de Coordenação de Cursos (CoC), nos termos do artigo 64 do Estatuto da USP"

${ }^{4}$ Caberá à Faculdade de Educação, além de participar dos diversos órgãos ligados à licenciatura, organizar internamente uma Comissão de Acompanhamento das Licenciaturas. A criação desta Comissão se justifica em razão do elevado número de alunos atendidos, da diversidade de cursos de licenciatura de que é parceira e da necessidade de articulação de sua ação formadora e de sua participação nas diversas instâncias organizadoras da formação de professores na universidade.

5 Ao fixar as exigências legais para os cursos de formação de professores, o Conselho Nacional de Educação, na Resolução CNE/ $\mathrm{CP} \mathrm{n}^{\circ} 2 / 2002$, estabelece que os cursos de licenciatura, de graduação plena, devem garantir em seus projetos pedagógicos quatro "componentes comuns": 1) prática como componente curricular, com duração mínima de 400 horas; 2) estágio curricular supervisionado, com duração mínima de 400 horas; 3) conteúdos curriculares de natureza científico-cultural, com duração mínima de 1.800 horas; e 4) atividades acadêmico-científicoculturais, com duração mínima de 200 horas, totalizando pelo menos 2.800 horas, ao longo de, no mínimo, três anos (Brasil. CNE, 2002b).
} 
quatro blocos de disciplinas e atividades que correspondem a diferentes dimensões da formação dos alunos das licenciaturas e se articulam com os componentes comuns previstos na legislação: os "estágios supervisionados", a "prática como componente curricular", as "atividades acadêmico-científico-culturais" e os "conteúdos curriculares de natureza científico-cultural". Os blocos constituem-se em:
Bloco I - Formação Específica: disciplinas e atividades diretamente relacionadas aos conhecimentos da área específica.
Bloco II - Iniciação à Licenciatura: disciplinas e atividades introdutórias à formação do professor da educação básica.
Bloco III - Fundamentos Teóricos e Práticos da Educação: disciplinas e atividades relacionadas à formação pedagógica em geral.
Bloco IV - Fundamentos Metodológicos do Ensino: disciplinas e atividades relacionadas ao ensino das áreas específicas. (USP, 2004, p. 18).

Cada unidade da USP pode decidir por uma proposta pedagógica que contemple os princípios e objetivos do PFP, bem como as exigências das diferentes áreas de conhecimento e formação profissional. Com a definição dessa organização curricular marcada por quatro blocos de disciplinas e atividades, a CPL considerou a boa formação específica do bacharel perfeitamente compatível com a sólida formação voltada para a docência na educação básica e profissional.

A fim de orientar a distribuição dos componentes comuns, o PFP faz uma primeira distinção entre a "prática como componente curricular" e o "estágio curricular supervisionado".

Em relação ao estágio curricular supervisionado, a Resolução CNE/ $\mathrm{CP}^{\circ} 2$ (Brasil. CNE, 2002b) destaca que ele se caracteriza por

... uma relação pedagógica entre alguém que já é um profissional reconhecido em um ambiente institucional de trabalho e um aluno estagiário (...). É um momento de formação profissional do formando seja pelo exercício direto in loco, seja pela presença participativa em ambientes próprios de atividades daquela área profissional sob a responsabilidade de um profissional mais habilitado. Ele não é uma atividade facultativa, sendo uma das condições para a obtenção da respectiva licença.

Assim, a CIL considera o estágio supervisionado como uma atividade formativa necessariamente ligada a uma atividade ou trabalho de campo que deverá ser executado prioritariamente em contato direto com as "unidades escolares dos sistemas de ensino", como preconiza a Resolução $\mathrm{CNE} / \mathrm{CP} \mathrm{n}^{\circ}$ 2/2002. Ele pode, contudo, recorrer a outras instituições consideradas diretamente relevantes para a formação docente, desde que regulamentado pelas respectivas CoCs ou pela CAL/FE.

Um fator de mudança diz respeito aos estágios supervisionados voltados para a mobilização de ações que incorporam as práticas concretas, 
uma forma de o futuro docente aprender a lançar um novo olhar sobre os gestos profissionais, dando-lhes maior destaque e visibilidade, enquanto ponto de partida do concreto pensado e fator de desenvolvimento profissional (García, 1994). Nessa perspectiva, o estágio supervisionado tem um papel de elemento integrador na formação do professor, oferecendo ao estudante de licenciatura oportunidades de ampliar e utilizar as habilidades e os conhecimentos adquiridos no curso para responder às necessidades e aos desafios da realidade escolar. O estágio supervisionado é distribuído entre diversas disciplinas que integram o Programa de Formação de Professores - sejam elas ligadas aos institutos de origem ou aos departamentos responsáveis pelas disciplinas pedagógicas. Suas atividades não devem ser fragmentadas e justapostas, mas ligadas aos projetos de formação de professores em vigência nas unidades da USP. ${ }^{6}$

A responsabilidade pela organização dos estágios curriculares é compartilhada entre as unidades de origem e os departamentos (ou Faculdade de Educação) responsáveis pelas disciplinas pedagógicas, cabendo a estes últimos a organização e a regulamentação de 300 horas e às unidades específicas, as 100 horas restantes. Sua supervisão compete sempre aos docentes da universidade, e as horas-aula dedicadas à supervisão direta do estágio podem ser consideradas como parte integrante das 400 horas exigidas por lei. Em ambos os casos, as CoCs - e, no caso do campus de São Paulo, a CAL/FE - devem promover a necessária integração entre os projetos de estágio.

Em relação à prática como componente curricular, o Programa assim se manifesta:

[...] a prática como componente curricular, em seu sentido amplo - que não se confunde com a antiga disciplina "Prática de Ensino", então ligada aos estágios - deve ser entendida como o conjunto de atividades ligadas à formação profissional, inclusive as de natureza acadêmica, que se voltam para a compreensão das práticas educativas e de aspectos variados da cultura das instituições educacionais e suas relações com a sociedade e com as áreas de conhecimento específico. (USP, 2004, p. 28).

Nesse sentido, o PFP contempla, em sua estrutura curricular, uma carga horária de "práticas como componentes curriculares" ao longo de todo o curso, maximizando as chances de conhecimento e inserção dos alunos junto às diferentes realidades da escola básica e profissional.

A seguir, apresentaremos os casos de implantação das propostas em duas unidades da USP: a Escola Superior de Agricultura "Luiz de Queiroz" (Esalq) e o Instituto de Ciências Matemáticas e da Computação (ICMC).

\section{A Escola Superior de Agricultura "Luiz de Queiroz" e seus programas de licenciatura em Ciências Agrárias e Ciências Biológicas ${ }^{7}$}

A Escola Superior de Agricultura "Luiz de Queiroz" (Esalq) - campus USP de Piracicaba - criou, em 1995, o Programa de Licenciatura em $\overline{6 \text { Como está explicitado na }}$ presente proposta de Programa de Formação de Professores, o estágio supervisionado se estabelece preferencialmente por vínculos institucionais entre a universidade e as escolas de educação básica, de forma a tornar necessária a participação dos diferentes atores sociais envolvidos num determinado projeto. Nesse sentido, todos têm responsabilidades específicas, mas caberá aos professores desta universidade a coordenação do processo, tal como hoje ocorre.

7 Versão deste trabalho foi apresentada no Encontro Nacional de Didática e Prática de Ensino (Endipe) ocorrido em Recife, Estado de Pernambuco, em abril de 2006. 
Ciências Agrárias, com o objetivo de conferir habilitação pedagógica para alunos dos cursos de Engenharia Agronômica e Engenharia Florestal da Esalq interessados em atuar na educação profissional em Ciências Agrárias nos diferentes níveis e modalidades de ensino formal e não formal.

O trabalho desenvolvido pela equipe de docentes da Esalq, com a formação de professores em Ciências Agrárias, tem possibilitado o envolvimento dessa unidade de ensino superior com a rede de escolas técnicas agrícolas do Estado de São Paulo, coordenada pelo Centro Estadual de Educação Tecnológica Paula Souza (Ceeteps), e com outras entidades, organizações e instâncias de governo municipal preocupadas com áreas emergentes, como a educação ambiental.

A licenciatura em Ciências Agrárias deve abrigar, no processo de formação de seus professores, espaço para a organização coletiva de educadores em torno de um novo modelo de ensino/escola técnica em agropecuária e meio ambiente, que atenda aos alunos de forma indistinta, competente e compatível com as novas demandas do mundo do trabalho, de uma agricultura e do agronegócio que se modernizaram e de um mercado consumidor ativo e preocupado com produtos e processos menos agressivos ao meio ambiente.

Esses desafios se somaram às dificuldades inerentes à implantação das diretrizes do PFP, o que incitou um período de análises sistemáticas e avaliação dos resultados obtidos em cada etapa dessa citada implantação.

\section{Discussão e aprovação}

Durante a apreciação do Programa de Formação de Professores (PFP) da USP pela Comissão de Graduação da Esalq, foi deliberado que a coordenação do programa de licenciatura elaborasse um projeto que demonstrasse o impacto das reformulações propostas pela Comissão Permanente de Licenciatura (CPL) da USP na estrutura curricular dos cursos de graduação da Esalq que ofereciam a licenciatura como opção de formação pedagógica.

Cabe destacar, como uma primeira grande alteração, a transferência do Programa de Licenciatura da Esalq para o período noturno, atendendo os discentes do curso de Ciências Biológicas, criado em 2002, e também os alunos de Engenharia Agronômica e Engenharia Florestal, que passam a poder cursar a licenciatura sem prejuízo das demais disciplinas oferecidas no bacharelado.

O "Projeto de Reformulação do Programa de Licenciatura/Formação de Professores da Esalq/USP" foi discutido no interior da unidade de ensino, que o aprovou com poucas sugestões de reformulação. As reformulações ocorreram no sentido de apresentar a disciplina "Introdução aos Estudos da Educação" como optativa para os cursos de bacharelado em Engenharia Agronômica e Engenharia Florestal e obrigatória para o curso de Ciências Biológicas. 


\section{Quanto aos princípios norteadores do projeto de formação de professores da USP}

Reiteramos os princípios norteadores do Projeto de Formação de Professores da USP, considerando o empenho que as unidades de ensino devem ter na elaboração de projetos integrados de preparação de docentes para a educação básica e para a educação profissional que incorporem a análise de especificidades, interesses e expectativas das instituições escolares envolvidas e que visem à promoção da qualidade da ação docente em seus diferentes graus e modalidades.

O Programa de Licenciatura da Esalq/USP envolve-se na formação de professores coletando e produzindo subsídios teóricos e práticos obtidos em projetos que integram alunos e professores em atividades de ensino, pesquisa e extensão, o que possibilita a oferta de estágios e vivências profissionais aos alunos durante todas as disciplinas referentes à formação pedagógica. Esses estágios são regulados pela legislação específica e por normas de convênio que a Esalq estabelece em contratos com as diferentes instituições que abrigam os alunos dos seus cursos de licenciatura.

Esses convênios de estágio também serão orientados por projetos de estágio devidamente discutidos e aprovados pelas escolas e/ou instituições parceiras.

A implantação do curso noturno de Ciências Biológicas na Esalq/USP, nas modalidades de bacharelado e licenciatura, no ano de 2002, significou um notável avanço na consolidação do espaço de formação de professores no interior dessa unidade da USP. A licenciatura na Esalq tem características específicas que elegem a interface da educação com o desenvolvimento rural e o meio ambiente como eixo formador. Dessa forma, parece possível afirmar que os projetos de formação incluirão atividade de ensino, pesquisa e extensão no sentido de refletir, propor e analisar intervenções educativas, formais e não formais, que resultem no aprimoramento da docência no campo das Ciências Agrárias e das Ciências Biológicas, tendo como pressuposto uma relação sustentável entre o homem e a natureza.

\section{Quanto aos objetivos do Programa de Formação de Professores da USP}

É necessário reafirmar os objetivos constantes do PFP da USP, no sentido de formar educadores comprometidos com a solução dos problemas da realidade da escola brasileira, de forma integrada com as questões emergentes que envolvam a educação profissional em Ciências Agrárias e em Ciências Biológicas.

Quanto à forma de ingresso para cursos de formação de professores na USP

$\mathrm{Na}$ Esalq/USP não existe ingresso específico para a licenciatura. Os alunos dos cursos de Engenharia Agronômica, Engenharia Florestal 
e Ciências Biológicas interessados na obtenção do diploma e na formação docente escolhem o conjunto de disciplinas optativas que a integralizam.

Contudo, mesmo não oferecendo ingresso específico para suas licenciaturas, a Esalq preocupou-se com a superação do modelo que prevê a licenciatura como uma superposição do conjunto de disciplinas do saber técnico, em que o aprendizado desse saber serve de pré-requisito para o aprendizado do saber pedagógico. É necessário que as unidades de ensino superior passem a refletir e propor estruturas alternativas que aprimorem a formação do profissional/professor baseadas na articulação das diretrizes para a formação de professores e nas diretrizes para a formação profissional nas áreas técnicas.

O conteúdo programático das disciplinas somado aos estágios orientados por projetos pedagógicos apresentados ao longo da graduação podem ser instrumentos úteis para a extinção da ideia de licenciatura como apêndice do bacharelado.

\section{Instituto de Ciências Matemáticas e de Computação (ICMC): uma experiência realista de mudança de paradigma na licenciatura em Matemática}

A partir das discussões promovidas desde o ano de 2000 e das novas propostas do MEC para os cursos de formação de professores (Resolução CNE/CP no 1/2002), um amplo debate nacional se abriu com relação às licenciaturas, em particular com relação às licenciaturas em Matemática. O recente processo de confecção de diretrizes curriculares para esses cursos suscitou opiniões dicotômicas entre os matemáticos acadêmicos e os educadores matemáticos sobre a formação de professores do ensino básico. Muitos dos primeiros fazem críticas à formação inicial proporcionada nas licenciaturas, alegando que os jovens não saem preparados nas matérias de Matemática que vão ensinar. Por outro lado, educadores também levantam o temor de que tudo o que ensinam e debatem durante essa formação seja "varrido pelo conservadorismo da prática de ensino" (Ponte, 2002, p. 3-4). Os jovens professores criticam essa formação, questionando se ela lhes serviu de alguma coisa, na maior parte das vezes, levando adiante uma concepção de que só a prática de sala de aula realmente importa.

No cenário internacional, Lambert e Ball (1998, apud Ponte, 2002, p. 5), em suas pesquisas como educadoras matemáticas norte-americanas, já traçavam um diagnóstico problemático da formação inicial de professores, resultantes de alguns fatores por elas levantados:

1) a pouca atenção dada, nessa formação, às crenças, às concepções e aos conhecimentos que os futuros professores trazem para o curso;

2) o fato de esse curso, geralmente, dar a impressão de que para ensinar é preciso pouco mais que o senso comum, isto é, de não mostrar a necessidade de um conhecimento profissional; 
3) não dar a devida atenção ao conhecimento didático;

4) separarem teoria e prática, tanto temporal quanto conceitualmente;

5) darem reduzida importância à prática profissional.

Sztajn (2002) também levanta o fato de que essa temática vem sendo amplamente discutida desde os anos 1990 pelos educadores matemáticos, principalmente nos Estados Unidos, desde que Shulman $(1986,1987)$ propôs um elo entre os saberes pedagógicos e aqueles do conteúdo específico, através do que chamou de "saber pedagógico disciplinar" (ou "conhecimento da didática do conteúdo" ou, ainda, "conhecimento pedagógico do conteúdo", como preferem algumas traduções em português). Para Sztajn, as pesquisas depois de Shulman provocaram uma revisão no que significa dizer que "um professor sabe matemática", e a pergunta sobre o que precisa saber um professor de Matemática passou a inquietar formadores de professores, não estando ainda definitivamente respondida. Segundo essa autora, responder "o que" depende de localizarmos "onde", "quando" e "por que" se dá essa formação.

Assim, neste cenário efervescente da educação matemática mundial, somam-se ainda as contingências locais em que esses cursos de licenciatura se desenvolvem e a necessidade de adequar as propostas formais feitas pelos acadêmicos e pelas políticas públicas de educação a um projeto pedagógico realista, que leve em conta essas contingências e as reais necessidades dos alunos (futuros professores) e das instituições existentes, sejam essas as instâncias de ensino superior onde ocorre a formação inicial desses professores ou aquelas em que eles vão atuar, as de educação básica.

Neste artigo, apresentamos uma proposta de curso de formação inicial em Matemática que procura levar em conta as mudanças de paradigmas que estão sendo discutidas para a formação profissional de professores da área, mas também que considere as contingências locais, a fim de construirmos uma proposta pedagógica que seja factível e bem localizada no tempo e no espaço em que se desenvolve.

Falamos do Curso de Licenciatura em Matemática do Instituto de Ciências Matemáticas e de Computação (ICMC) da Universidade de São Paulo, em São Carlos, SP. Foi criado em 1990 e tem passado por uma série de reformulações desde então. Embora não se possa dizer que ele, desde sua criação, tivesse características do modelo " $3+1$ " (três anos de disciplinas de bacharelado e mais um ano de disciplinas pedagógicas), o curso ainda não estava completamente ajustado ao Programa de Formação de Professores (PFP) da USP e às novas normas para os cursos de formação de professores do MEC (Brasil. CNE, 2002a).

Para fugir a esse modelo e atendermos às novas propostas do MEC e da Universidade de São Paulo, já no ano de 2004, realizamos uma série de alterações na estrutura curricular. A nossa licenciatura em Matemática tem por objetivos gerais: a formação profissional inicial de professores de Matemática para o segundo ciclo do ensino fundamental e para o ensino 
médio; proporcionar ao futuro professor uma visão ampla do conhecimento matemático e pedagógico, para que ele possa especializar-se depois em sua formação continuada e/ou em nível de pós-graduação em uma das áreas afins.

Para atingir esses objetivos, procuramos articulá-los a atividades e disciplinas em um projeto pedagógico que levasse em conta a realidade local no que diz respeito ao corpo docente da instituição proponente, às vocações da comunidade acadêmica envolvida e às demandas por profissionais e ofertas de formação locais, além das recomendações contidas nos documentos anteriormente citados.

\section{O projeto pedagógico}

Com os objetivos anteriores em mente, procuramos elaborar um projeto pedagógico que seja capaz de integrar todas essas metas em um conjunto articulado não apenas de disciplinas, mas também de atividades de estágio e atividades acadêmico-científico-culturais.

O ingresso dos alunos em nosso curso, mesmo após as recentes mudanças, continua articulando as opções para o bacharelado e a licenciatura, pois acreditamos que os alunos iniciantes não têm informações suficientes e maturidade, no período do ensino médio, para fazer essa opção logo no momento do vestibular. Ponte (2002) também relata, em sua experiência com o curso da Faculdade de Ciências, em Lisboa, que os três primeiros anos deste também são muito semelhantes ao bacharelado, o que permite a mudança dos alunos entre um curso e outro. Desse modo, em nossa licenciatura, essas duas habilitações permanecem com semestres comuns, podendo o aluno optar por uma ou outra ao final do $3^{\circ}$ período letivo. Após concluir uma das opções, o estudante tem o direito de complementar sua formação, caso deseje, para obter um segundo diploma na outra (note-se que ele pode concluir primeiro a licenciatura e depois o bacharelado, se desejar).

Outro diferencial interessante é que, durante seu $1^{\circ}$ semestre letivo, todos os alunos que fizerem opção pela carreira "Matemática" no ICMC (bacharelado/licenciatura em Matemática e bacharelado em Matemática Aplicada e Computação Científica) devem cursar uma disciplina comum "Matemática do ensino básico: abordagem crítica", que faz parte do Bloco II de disciplinas introdutórias à temática educacional do Programa de Formação de Professores da USP (2004, p. 18).

No segundo semestre, os alunos cursam uma outra disciplina comum "Introdução aos estudos da educação", agora dirigida apenas ao bacharelado/licenciatura em Matemática, e não mais à Matemática Aplicada, cujo objetivo é fornecer uma visão atual dos problemas da educação brasileira e dos possíveis projetos e ações para uma educação cidadã que promova valores e aptidões mais amplos para a real inserção dos jovens na sociedade, por meio de uma participação consciente, crítica e reflexiva. 


\section{As disciplinas de natureza científica e a formação específica}

Neste conjunto, nomeado como Bloco I no Programa de Formação de Professores da USP, o aluno da licenciatura em Matemática cursa 1.830h em disciplinas organizadas nos seguintes núcleos:

a) Núcleo de Formação em Matemática

É constituído de 12 disciplinas obrigatórias, tais como: Cálculo, Geometria, Álgebra, Equações Diferenciais Ordinárias, Análise, Elementos de Matemática etc. Neste núcleo, o aluno pode escolher uma ou duas optativas num rol de 14 disciplinas.

b) Núcleo de Formação em Física

É constituído de três disciplinas obrigatórias em Física Básica (Mecânica e Eletricidade), que procuram se articular com os conhecimentos matemáticos de nível superior adquiridos pelos licenciandos e com algumas de suas aplicações na Física.

c) Núcleo de Formação em Computação/Cálculo Numérico/Probabilidade

Este é formado por duas disciplinas básicas de Programação de Computadores e Algoritmos, duas de Cálculo Numérico e uma de Introdução à Teoria das Probabilidades, totalizando cinco disciplinas obrigatórias. O aluno pode cursar também, como optativas, Inferência Estatística e Programação Matemática, além de outras complementares.

d) Núcleo de Formação em Educação Matemática

Uma disciplina obrigatória (Prática de Ensino de Geometria e Desenho Geométrico) e mais quatro optativas podem ser escolhidas (Filosofia da Matemática, Filosofia da Educação Matemática, Ensino de Matemática por Múltiplas Mídias e História da Matemática).

Este bloco de disciplinas está ligado fortemente às competências que o futuro professor deverá desenvolver a partir do conhecimento e domínio dos conteúdos básicos relacionados à área de Matemática, algumas áreas afins, e às teorias educacionais, de modo a poder compartilhar saberes docentes de diferentes áreas/disciplinas e articulá-los em seu trabalho.

\section{As práticas como componentes curriculares}

Na licenciatura em Matemática do ICMC, os alunos devem cumprir 405h em atividades designadas "práticas como componentes curriculares". Estas se inserem no Bloco III do PFP, englobando fundamentos teóricos e práticos da educação, mas que sempre procuram se articular com as 
questões relacionadas às vivências e às práticas de um professor de Matemática. Da carga total desse conjunto de disciplinas (480 horas), apenas 75 horas são destinadas à teorização. Portanto, esse é um fator diferencial em nosso curso, uma vez que essas disciplinas têm um caráter reflexivo, porém sempre articulado com pesquisas e situações que envolvem as práticas docentes e suas relações com os alunos, a escola, as organizações institucionais e a comunidade.

Estas disciplinas são: Análise Crítica de Livros Didáticos (4 ca + 2 ct), ${ }^{8}$ Psicologia da Educação (4 ca +2 ct), Estrutura e Funcionamento dos Ensinos Fundamental e Médio ( 4 ca +2 ct) e Didática (4 ca +2 ct).

\section{Os estágios supervisionados}

Os estágios obrigatórios são desenvolvidos nas disciplinas por nós designadas como "Práticas de Ensino" (num total de 420 horas) e que envolvem discussões de ordem teórico-metodológica e se propõem integrar os futuros professores à realidade escolar atual, por meio dos convênios firmados com várias escolas da cidade de São Carlos. São elas: Prática de Ensino de Matemática I (2 ca +4 ct), Prática de Ensino de Matemática II (2 ca +4 ct) e Prática de Ensino de Geometria e Desenho Geométrico (1 ca +2 ca +4 ct). Esta última tem um de seus créditos computados para a formalização de conteúdos da Geometria e do Desenho Geométrico, contados no Bloco I.

Tais disciplinas, classificadas dentro do Bloco IV do PFP, também são articuladas com as demais. Nos momentos de estágio supervisionado, os alunos poderão agregar suas ações aos Projetos Integrados já iniciados nas quatro disciplinas do Bloco III, que são anteriores a elas na estrutura curricular, encerrando, assim, um ciclo de reflexões geradas em diversos âmbitos e momentos de sua vivência como futuro profissional do ensino e educador matemático.

Entendemos que a relação entre saber Matemática e o seu ensino (Sztajn, 2002, p. 22) não é linear. No momento de ensinar, todos esses saberes interagem com as visões do professor sobre o processo de ensino-aprendizagem, os alunos e o contexto da sala de aula. Desse modo, entendemos que, embora aqui organizadas em blocos separados, essas disciplinas não têm uma fronteira rígida, e os projetos integrados nelas propostos são as pontes de ultrapassagem dessas fronteiras, exigindo grande preparo também por parte dos formadores de professores de Matemática.

\section{As atividades acadêmico-científico-culturais}

Os alunos da licenciatura em Matemática deverão, ainda, complementar sua formação com 200 horas de atividades acadêmico-científico-culturais, totalizando uma carga-horária de 2.855 horas de dedicação, em período integral, durante quatro anos. Essas atividades podem ser contadas dentro das seguintes opções: iniciação científica, monitorias, bolsas-trabalho, participação em congressos de matemática, educação ou educação
8 ca = crédito-aula; $\mathrm{ct}=$ crédito-trabalho. 
matemática, participação em palestras locais e atividades de extensão - com comprovantes. Também estudamos a possibilidade de incorporar nesse quesito, futuramente, as visitas científicas monitoradas.

Para que possamos dar corpo a essas mudanças curriculares e implementá-las com qualidade, algumas ações conjuntas também têm sido buscadas nos cursos do ICMC. Entre essas mudanças, podemos citar o empenho na redução da evasão e a reforma dos laboratórios de ensino.

Por esses motivos, nossa estrutura curricular apresenta uma carga horária dentro das exigências mínimas do MEC (Resolução CNE/CP nº 1/2002), uma vez que é nosso objetivo fornecer todas as condições para que o futuro professor de Matemática tenha flexibilidade para buscar novas formas e fontes de aprendizagem que não apenas as da sala de aula, gerenciando o próprio desenvolvimento profissional por meio de projetos pessoais de estudos (Pires, 2002).

\section{Considerações finais e perspectivas}

É preciso que o compromisso assumido formalmente pelas unidades e pela Pró-Reitoria de Graduação da USP, quando da apresentação do Programa de Formação de Professores, passe a se expressar, em termos práticos, em uma política geral de formação de professores e profissionais comprometidos com a educação pública básica. Sabemos que uma política não se implanta pelo rigor legal, mas perpassa a cultura institucional em direção a uma utopia. Temos um longo caminho a percorrer, pois a história da formação de professores no País foi construída num movimento pendular e de crise. Neste momento, a CIL atua na direção de imprimir maior visibilidade, estímulo e valorização da identidade das licenciaturas. As possibilidades de efetivação de novas propostas formativas têm surgido em cenários formativos e coletivos, o que pode assegurar-lhes maior possibilidade de sucesso.

A análise dos processos geradores de mudanças nos cursos de licenciaturas tem contribuído para a localização de pontos críticos das propostas vigentes e para a ressignificação da concepção de professor de licenciatura.

Concluímos este relato com a convicção de que as reformas para as licenciaturas se constituem processos dinâmicos e devem ser alvo de constantes revisões que gerem novas propostas. Portanto, os projetos do ICMC e da Esalq não estão acabados, mas um significativo passo foi dado para a valorização da formação de professores desses cursos no sentido de que sejam capazes de reconstruir saberes, propor novas perguntas e paradigmas para a educação brasileira, com todas as peculiaridades e dificuldades que envolvem esse desafio.

\section{Referências bibliográficas}


do Ministro da Educação que altera a estrutura atual das licenciaturas. Campinas, SP, 2007. Disponível em: < http:// lite.fae.unicamp.br/ anfope/htm>. Acesso em: 2 jul. 2008.

BOURDIEU, P. Razões práticas: sobre a teoria da ação. Campinas, SP: Papirus, 1997.

BRASIL. Conselho Nacional de Educação. Resolução no 1, de 18 de fevereiro de 2002. Diretrizes curriculares nacionais para a formação de professores da educação básica, em nível superior, curso de licenciatura, de graduação plena. 2002. Disponível em: < portal.mec. gov.br/seesp/arquivos/pdf/res1_a.pdf>.

Resolução no 2, de 19 de fevereiro de 2002. Duração e carga horária dos cursos de licenciatura, de graduação plena, de formação de professores da educação básica em nível superior. 2002. Disponível em: < portal.mec.gov.br/cne/arquivos/pdf/CP022002.pdf>.

GARCIA, Carlos Moreno. Formación del profesorado para el cambio educativo. Barcelona: PPU, 1994.

LAMBERT, M.; BALL, D. L. Teaching, multimedia and mathematics. New York: Teachers College Press, 1998.

PAVANELLO, R. M.; ANDRADE, R. N. G. Formar professores para ensinar geometria: um desafio para as licenciaturas em Matemática. Educação Matemática em Revista, SBEM, São Paulo, v. 9, n. 11A, edição especial, p. 78-87, 2002.

PENIN, S. T. S. A formação de professores e a responsabilidade das universidades. Estudos Avançados, USP, São Paulo, v. 15, n. 42, p. 317-332, 2001.

PEREIRA, J. E. D. Formação de professores: pesquisa, representações e poder. Belo Horizonte, MG: Autêntica, 2000.

PIPITONE, M. A. P. O programa de licenciatura em ciências agrárias da Esalq/USP e a educação profissional. In: KRASILCHIK. M. (Org.). USP fala sobre Educação. São Paulo: USP, Pró-Reitoria de Pesquisa, 1999. p. 54-60.

PIRES, C. M. C. Reflexões sobre os cursos de licenciatura em Matemática. Educação Matemática em Revista, SBEM, São Paulo, v. 9, n. 11A, edição especial, p. 44-56, 2002.

PONTE, J. P. A vertente profissional da formação inicial de professores de Matemática. Educação Matemática em Revista, SBEM, São Paulo, v. 9, n. 11A, edição especial, p. 3-8, 2002. 
RIVAS, Noeli P. P. As reformas curriculares no processo de constituição das escolas de formação de professores no Estado do Paraná. 2003. 293p. Tese (Doutorado em Psicologia) - Universidade de São Paulo (USP), 2003.

SHULMAN, L. Those who understand: knowledge growth in teaching. Educational Researcher, Washington, v. 15, n. 2, p. 4-14, 1986.

SHULMAN, L. Knowledge and teaching: foundations of the new reform. Harvard Educational Review, v. 57, n. 1, p. 1-22, feb. 1987.

SOLÉ, I.; COLL, C. Os professores e a concepção construtivista. In: COOL, C. et al. O construtivismo na sala de aula. 6. ed. São Paulo: Ática, 2003. p. 10-28.

SZTAJN, P. O que precisa saber um professor de Matemática? Uma revisão da literatura americana dos anos 90. Educação Matemática em Revista, SBEM, São Paulo, v. 9, n. 11A, edição especial, p. 17-28, 2002.

UNIVERSIDADE DE SÃO PAULO (USP). Pró-Reitoria de Graduação. Programa de formação de professores. São Paulo, 2004.

. Diretrizes da Pró-G: biênio 2000-2002. São Paulo, 2000.

VALENTE, W. R. História da Matemática na licenciatura. Educação Matemática em Revista, SBEM, v. 9, n. 11A, edição especial, p. 88-94, 2002.

Maria Angélica Penatti Pipitone, doutora em Educação pela Universidade Estadual de Campinas (Unicamp), é professora e coordenadora da Escola Superior de Agricultura Luiz de Queiroz (Esalq), campus USP de Piracicaba.

pipitone@esalq.usp.br

Edna Maura Zuffi, doutora em Educação pela Universidade de São Paulo, é professora do Departamento de Matemática e coordenadora do Curso de Licenciatura em Matemática do Instituto de Ciências Matemáticas e de Computação (ICMC) do campus USP de Piracicaba.

edna@icmc.usp.br

Noeli Prestes Padilha Rivas, doutora em Psicologia pela Universidade de São Paulo, é professora e coordenadora do Curso de Licenciatura em Pedagogia da Faculdade de Filosofia, Ciências e Letras do campus USP de Ribeirão Preto.

noerivas@ffclrp.usp.br

Recebido em 25 de novembro de 2008.

Aprovado em 15 de dezembro de 2009. 